\title{
The non-linear relationship between nerve conduction velocity and skin temperature
}

\author{
K TODNEM,* G KNUDSEN, $†$ T RIISE, H NYLAND,* J A AARLI* \\ From the Department of Neurology,* Haukeland Hospital, University of Bergen, Norwegian Underwater \\ Technology Centre, $\dagger$ and Section for Medical Informatics and Statistics, $\ddagger$ University of Bergen, Bergen, Norway
}

SUMMARY Median motor and sensory nerves were examined in 20 healthy subjects. Superficial stimulating and recording electrodes were used, and the nerves were examined at natural skin temperature, after cooling and after heating of the arm. The conduction velocity for the fastest and slow conducting sensory fibres (temperature range $17-37^{\circ} \mathrm{C}$ ), and for the fastest conducting motor fibres (temperature range $19-38^{\circ} \mathrm{C}$ ) increased non-linearly with increase in skin temperature. Similarly, distal motor latencies increased non-linearly with decrease in skin temperature. The effect of temperature was most pronounced in the low temperature range, and change in conduction velocity per degree centigrade was reduced toward higher skin temperature. Sensory nerve response duration increased linearly with decline in skin temperature. Sensory and motor amplitude did not show any significant relation to skin temperature.

Nerve conduction studies have been performed in animals since $1850 .^{\prime}$ Techniques for the examination of motor nerve function in man have been established since 1948, and for sensory nerve function since $1956,{ }^{23}$ and have later been improved. They are now widely used both in routine clinical investigation of nerve and muscle disorders, and for investigation of the possible physiological changes in nerves exposed to altered environmental influences.

Temperature changes influence peripheral nerve function. To what extent and whether the effect is the same along the temperature scale, is still disputed. ${ }^{14-16}$ Nerve conduction studies are usually performed using surface electrodes, and as distal skin temperature varies, the effect of temperature is important both in routine neurophysiology and as an aspect of nerve physiology.

The aim of this study was therefore to evaluate the influence of temperature changes on normal human sensory and motor nerve conduction, and to compare the results obtained to previous studies.

\section{Material and method}

\section{Subjects}

Twenty healthy, normally built volunteers, 14 males and six females, age 21 to 40 years (mean $30 \cdot 5$ ), height 159 to $188 \mathrm{~cm}$

Address for reprint requests: $\operatorname{Dr} K$ Todnem, Department of Neurology, 5021 Haukeland Hospital, Bergen, Norway.

Received 1 July 1988 and in revised form 10 October 1988. Accepted 17 October 1988 (mean 176) were examined. They had no signs or symptoms of neurological impairment. Informed consent was obtained by all subjects, and no complications occurred.

Equipment used was a Neuromatic 2000C, Dantec, Denmark.

\section{The median sensory nerve}

Stimulation Ring electrodes were applied to the index finger. The stimulus duration was $0.2 \mathrm{~ms}$ and the pulse given at a frequency of $1 \mathrm{~Hz}$. Subjective sensory threshold was determined and the stimulus intensity was supramaximal at approximately three times subjective sensory threshold (8$11 \mathrm{~mA})$.

Recording The sensory potentials were recorded $14 \mathrm{~cm}$ proximal to the metacarpophalangeal joint at the volar side of the wrist, with a superficial bipolar electrode. Twenty single sweeps were averaged.

Latencies were measured from the stimulus artifact to the take off for the first peak of the averaged potential (start), and to the ultimate return of the wave to the baseline (end). Latencies to the start of the averaged potential represent the fastest conducting sensory fibres, while the slower conducting fibres are represented by the latencies to the end of the potential. ${ }^{17}$ In this study we have applied these definitions for fast and slow conduction. However, using a surface electrode we did not obtain the latencies for the slowest conducting fibres.

The amplitude of the sensory response was measured from peak to peak. The response duration was measured from the first take off to the ultimate return of the wave to the baseline.

The median motor nerve

Stimulation The nerve was stimulated percutaneously at the volar side of the wrist and elbow with a bipolar surface electrode. The stimulus duration was $0.2 \mathrm{~ms}$, frequency $1 \mathrm{~Hz}$ 
and supramaximal intensity $(9-25 \mathrm{~mA})$.

Recording The muscle compound action potential (Mresponse) was recorded from the abductor pollicis brevis with a bipolar surface electrode.

Latencies Distal motor latency was measured from the stimulus artifact to the initial deflection of the M-response. The onset of the M-response represents conduction in the fastest motor fibres. ${ }^{31819} \mathrm{~F}$-responses were recorded as the difference between absolute F-response and distal latency (sometimes known as "M-F latency"). The shortest F-response latency was used. The amplitude of the M-response was measured from peak to peak.

Temperature Skin temperatures were recorded with thermistors (Yellow Spring Instruments, Thermistor Series $709 \mathrm{~A}$, given accuracy of $\pm 0.15^{\circ} \mathrm{C}$, Yellow Spring, USA). The thermistors were taped to the skin (one to the tip of the third finger, one in the palm, one approximately $10 \mathrm{~cm}$ proximally to the wrist, and one at the elbow), and connected to an electronic temperature measuring device (SINTEF, Norway), for digital read-out. The temperatures were also continuously registered on a recorder (Watanabe Multicoder MC 6601, Japan). Temperature measurements were performed simultaneously during the nerve examination. For the

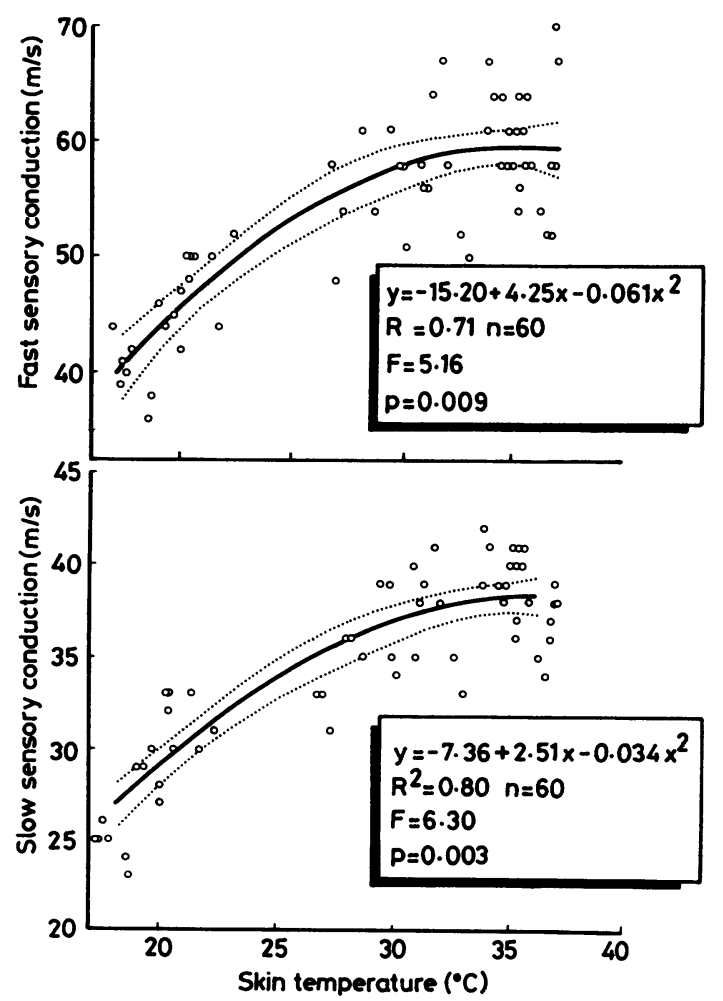

Fig 1 Conduction velocity for fast (upper) and slow (lower) conduction of the median sensory nerve at different temperatures. The least-square polynomial regression line of second power and its $95 \%$ confidence interval are given. Insert: regression equation. sensory and motor nerve examinations, the three distal (finger, palm, wrist) or the three proximal (palm, wrist, elbow) temperature points were used, respectively.

Examination procedure The subjects were examined in supine position in an air-conditioned room with air temperature approximately $25^{\circ} \mathrm{C}$. Three examinations were performed on each individual; at normal, low and high skin temperatures. The first examination was made at the skin temperature obtained in the room where the examination took place. The second examination was made after cooling the arm using a tight anatomical plastic bag, filled with cold water and ice. The third examination followed after heating the arm with the same equipment and hot water. Recordings were made after the skin temperatures had been stable for 10 minutes, and performed immediately after removal of the cooling and heating equipment.

\section{Statistical methods}

Polynomial regression was used to describe the relationship between the nerve variables and skin temperatures. Each variable was tested with a first, second and third degree analysis. The appropriate degree polynomial was indicated by a goodness of fit test (F-test). ${ }^{20}$ Student's $t$ test was used to describe the difference between the conduction velocity in sensory and motor nerves.

\section{Results}

\section{Median sensory nerve:}

The range of the mean natural skin temperatures for the different subjects was $27-34^{\circ} \mathrm{C}$, after cooling $17-$ $27^{\circ} \mathrm{C}$ and after heating $34-37^{\circ} \mathrm{C}$ (temperature range $\left.17-37^{\circ} \mathrm{C}\right)$.

Conduction velocity increased in a non-linear fashion with increase in skin temperature both for fast and slow conduction (fig 1). The effect of temperature was most pronounced at low temperatures (table 1). The steepness of the regression lines were reliably different at different temperatures.

Response duration increased linearly with decline in skin temperature (fig 2). We could not demonstrate any significant deviation from linearity.

Amplitude $(r=0.08, p=0.6)$ and subjective sensory threshold $(r=-0 \cdot 13, p=0 \cdot 3)$ did not vary significantly with changes in skin temperature.

Table 1 Change in conduction velocity per degree centigrade at different skin temperatures for the median sensory and motor nerves (second degree polynomial regression analysis).

\begin{tabular}{lccl}
\hline Temperature $\left({ }^{\circ} \mathrm{C}\right)$ & $\begin{array}{l}\text { Sensory nerve } \\
\mathrm{m} / \mathrm{s}\end{array}$ & $\begin{array}{l}\text { Motor nerve } \\
\mathrm{m} / \mathrm{s}\end{array}$ & $\begin{array}{l}\text { Distal latency } \\
\mathrm{ms}\end{array}$ \\
\hline 20 & 1.8 & 1.4 & -0.28 \\
25 & 1.2 & 0.9 & -0.22 \\
30 & 0.6 & 0.4 & -0.15 \\
35 & 0 & -0.08 & -0.08 \\
37 & -0.2 & -0.28 & -0.05 \\
\hline
\end{tabular}




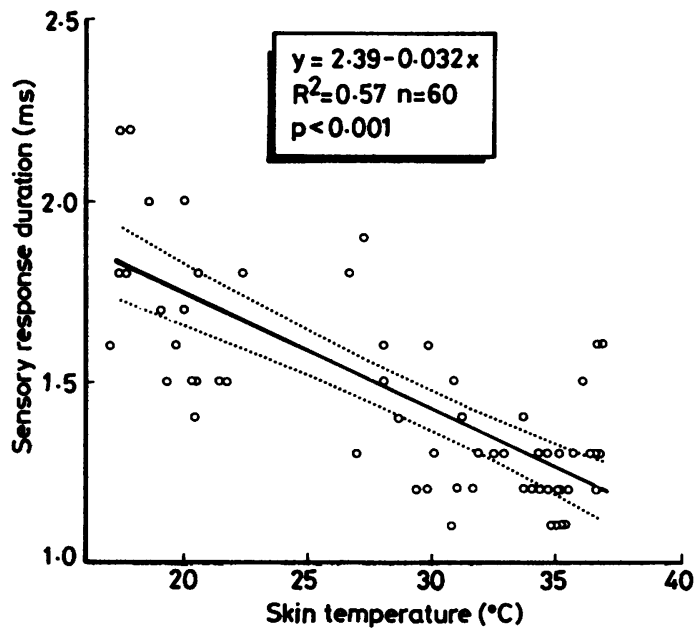

Fig 2 Response duration of the median sensory nerve at different temperatures. The least-square polynomial regression line of first power and its $95 \%$ confidence interval are given. Insert: regression equation.

\section{Median motor nerve}

The range of the mean natural skin temperature was $29-34^{\circ} \mathrm{C}$, after cooling $19-23^{\circ} \mathrm{C}$ and after heating $35-38^{\circ} \mathrm{C}$ (temperature range $19-38^{\circ} \mathrm{C}$ ).

Conduction velocity for fast conduction increased in a non-linear fashion with increase in skin temperatures (fig 3). The effect of temperature was most pronounced at low temperatures (table 1). The steepness of the

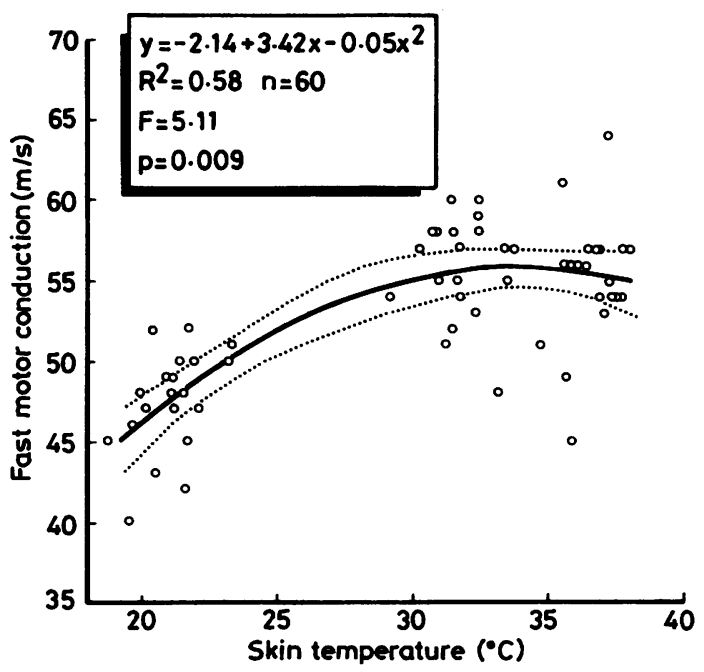

Fig 3 Fast conduction velocity of the median motor nerve at different temperatures. The least-square polynomial regression line of second power and its $95 \%$ confidence interval are given. Insert: regression equation.

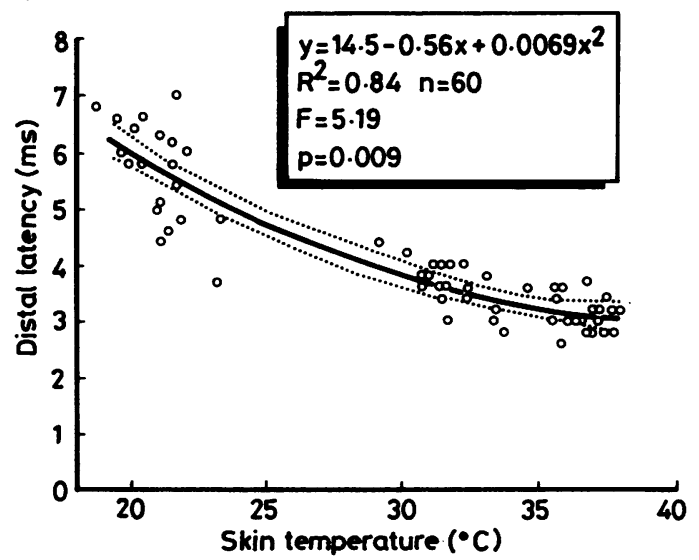

Fig 4 Distal latency of the median motor nerve at different temperatures. The least-square polynomial regression line of second power and its $95 \%$ confidence interval are given.

Insert: regression equation.

regression lines was reliably different at the different temperatures.

Distal latency increased with decline in skin temperature in a non-linear fashion (fig 4).

Response duration decreased non-linearly with increase in skin temperature, and was shortest at $31^{\circ} \mathrm{C}$ $\left(R^{z}=0.58, p<0.00005, F=14\right)$. Above that temperature response duration increased with increase in temperature.

Amplitude did not vary significantly with changes in skin temperature $(\mathrm{r}=-0 \cdot 25, \mathrm{p}=0.06)$.

$F$-response increased linearly with decline in skin temperature $(r=-0.56$, slope -0.24$)$. We could not demonstrate any significant deviation from linearity.

The normal values from the examination of the median sensory and motor nerves are listed in tables 2 and 3 . The nerve conduction velocity was significantly faster in sensory than in motor nerves $(p=0.03)$.

Age had no significant influence on fast sensory conduction velocity $(r=-0.38, p=0 \cdot 1)$, fast motor conduction velocity $(r=-0.24, p=0.3)$, distal latency $(r=0.43, p=0.06)$ or any other variable in this study.

Table 2 Neurophysiological variables of the median sensory nerve in 20 normal subjects. Mean skin temperature $30.6^{\circ} \mathrm{C}$ (range $26 \cdot 7-34 \cdot 1^{\circ} \mathrm{C}$ ).

\begin{tabular}{lllc}
\hline Variable & Unit & Mean value (SD) & Range \\
\hline Fast CV & $\mathrm{m} / \mathrm{s}$ & $58(5 \cdot 3)$ & $48-67$ \\
Slow CV & $\mathrm{m} / \mathrm{s}$ & $37(2 \cdot 9)$ & $33-42$ \\
Amplitude & $\mathrm{microV}$ & $11(4 \cdot 9)$ & $5 \cdot 2-23.4$ \\
Response duration & $\mathrm{ms}$ & $1 \cdot 4(0 \cdot 2)$ & $1 \cdot 1-1 \cdot 8$ \\
Sensory threshold & $\mathrm{mA}$ & $2 \cdot 2(0 \cdot 5)$ & $1 \cdot 2-3 \cdot 4$ \\
\hline
\end{tabular}

$\mathrm{CV}=$ conduction velocity. $\mathrm{SD}=$ standard deviation . 
Table 3 Neurophysiological variables of the median motor nerve in 20 normal subjects. Mean skin temperature $31.8^{\circ} \mathrm{C}$ (range 29.2-33.8).

\begin{tabular}{llcc}
\hline Variable & Unit & Mean value (SD) & Range \\
\hline Fast CV & $\mathrm{m} / \mathrm{s}$ & $56(3.1)$ & $48-60$ \\
Distal latency & $\mathrm{ms}$ & $3.6(0.4)$ & $2.8-4 \cdot 4$ \\
Amplitude & $\mathrm{mV}$ & $12.2(2.4)$ & $4.8-15 \cdot 8$ \\
Response duration & $\mathrm{ms}$ & $15.8(3.4)$ & $12-21.4$ \\
F-response & $\mathrm{ms}$ & $25.9(1.8)$ & $22.6-30.0$ \\
$\quad$ amplitude & $\mathrm{mV}$ & $0.9(0.5)$ & $0.3-1.7$ \\
\hline
\end{tabular}

$\mathrm{CV}=$ conduction velocity. $\mathrm{SD}=$ standard deviation.

\section{Discussion}

In contrast to what most authors have reported, ${ }^{9-1215}$ this study showed that the effect of temperature upon peripheral nerve function, within the temperature range tested, is not linear. Both fast and slow sensory conduction and fast motor conduction reacted with a non-linear increase in the conduction velocity to a rise in the skin temperature. The increase per centigrade increase in skin temperature was most pronounced in the lower temperature range. The distal motor latency also decreased non-linearly with increase in skin temperature. The changes were smaller as skin temperature approached normal values. However, the present data do not indicate whether the effect upon distal motor latencies is mainly due to an effect upon distal nerve conduction, neuromuscular transmission or impulse conduction in muscle tissue.

There are several technical problems when measuring nerve conduction velocity using surface electrodes; the placement of the stimulating cathode over the nerve, excessive spread of stimulation current and inaccuracies of surface measurements. ${ }^{12223}$ Such fallacies must be considered when normal values from different studies are compared. The obtained normal values in this study are comparable to previous reports. ${ }^{2922425}$ We have also shown, as have others, that the conduction velocity is significantly faster in the median sensory nerves than in the motor nerves. ${ }^{322}$ Needle electrodes have also been employed, but a comparison between the results using skin and needle electrodes showed only minor differences for conduction velocity, although amplitudes were considerably influenced. ${ }^{2425}$

The technique used for cooling and heating has additional flaws. We used superficial skin thermistors and kept temperatures stable for some time before the examination, but the skin temperature may not be identical to the nerve temperature. Near-nerve temperature measurements have revealed that there is a temperature gradient between skin and nerve. ${ }^{17}$ Since the relationship between skin temperature and nearnerve temperature at corresponding sites is linear, ${ }^{26}$ the use of skin temperature in this study should not affect the results.

The results from studies in animals have revealed that there are species-specific physiological temperature ranges for nerve conduction, and that nerve conduction will decrease or even cease both with low and high temperatures. ${ }^{521}$ Paintal investigated the saphenous and vagal nerve fibres in the cat, and found that the change in conduction velocity per degree change in temperature was most pronounced at very low temperatures. Our results indicate that human nerves react similarly.

Most authors examining human nerves have assumed that there is a linear relationship between nerve conduction velocity and skin temperature. Buchtal and Rosenfalck found that median sensory nerve conduction velocity for one nerve changed $2 \cdot 1$ $\mathrm{m} / \mathrm{s} /{ }^{\circ} \mathrm{C}$ between 23 and $36^{\circ} \mathrm{C}$. The change in conduction velocity for six nerves was $1.5 \mathrm{~m} / \mathrm{s} /{ }^{\circ} \mathrm{C}$ between 26 and $36^{\circ} \mathrm{C} .{ }^{9}$ Although they did not consider a nonlinear relationship, their data indicate that the conduction velocity change is greater at low temperatures.

Previous studies, aiming at the assessment of the change in nerve conduction velocity per degree change in temperature, are based on a linear relationship. ${ }^{1011526}$ Lowitzsch considered a non-linear relationship between nerve conduction velocity and skin temperature, but did not find it. He did, however, observe a non-linear relationship between temperature and the refractory period, with more pronounced temperature effect at low temperatures. ${ }^{12}$ In one human study a non-linear relationship was found between skin temperature and conduction velocity for the median and ulnar sensory nerves. ${ }^{14}$

Since temperature influences nerve conduction, efforts have been made to establish correction formulas for adjusting the nerve conduction velocity in subjects with low skin temperature." ${ }^{1526}$ These formulas are based upon the assumption of a linear relationship between nerve conduction velocity and skin temperature. The present data show, however, that this relationship is non-linear. One other study has revealed that sensory nerves seem to be more influenced by temperature than motor nerves, and that boy's nerves are more sensitive than girl's. ${ }^{16}$ Both sensory and motor nerve function varies with age. 22728 It can therefore be assumed that the influence of temperature on nerve conduction velocity is different in the different age groups. In addition, abnormal nerves, both from animals and humans, have a different sensitivity to change in skin temperature than normal nerves. ${ }^{813}$ Nerve conduction velocity is therefore influenced by many factors. The use of correction formulas to compute the correct value from values obtained at low skin temperature may thus be inaccurate. 
We are indebted to the staff of the Norwegian Underwater Technology Centre for valuable support and collaboration in the present investigation. The study was supported financially by the Royal Norwegian Council for Scientific and Industrial Research, Statoil and Norsk Hydro a.s.

\section{References}

1 Helmholtz $\mathbf{H}$ Von. Messungen uber den zeitlichen Verlauf der Zuckung animalischer Muskeln und de Fortpflanzungsgeschwindigkeit der Reizung in den Nerven. In: Muller J. Archiv fur Anatomie und Physiologie 1850:276-364.

2 Hodes R, Larrabee MG, German W. The human electromyogram in response to nerve stimulation and the conduction velocity of motor axons. Arch Neurol Psychiat 1948;60:340-65.

3 Dawson GD. The relative excitability and conduction velocity of sensory and motor nerve fibres in man. $J$ Physiol (Lond) 1956;131:436-51.

4 Gasser HS. Nerve activity as modified by temperature changes. Am J Physiol 1931;97:254-70.

5 Hodgkin AL, Katz B. The effect of temperature on the electrical activity of the giant axon of the squid. $J$ Physiol (Lond) 1949;109:240-49.

6 Douglas WW, Malcolm JL. The effect of localised cooling on conduction in cat nerves. $J$ Physiol (Lond) 1955;130:53-71.

7 Paintal AS. Block of conduction in mammalian myelinated nerve fibres by low temperature. $J$ Physiol (Lond) 1965;180:1-19.

8 Paintal AS. Effects of temperature on conduction in single vagal and saphenous myelinated nerve fibres of the cat. J Physiol (Lond) 1965;180:20-49.

9 Buchtal F, Rosenfalck A. Evoked action potentials and conduction velocity in human sensory nerves. Brain Res 1966;3:1-122.

10 McLeod JG. Digital nerve conduction in the carpal tunnel syndrome after mechanical stimulation of the finger. J Neurol Neurosurg Psychiatry 1966;29:12-22.

11 de Jesus PV, Hausmanowa-Petrusewicz I, Barchi RL. The effect of cold on nerve conduction of human slow and fast nerve fibres. Neurology 1973;23:1182-9.

12 Lowitzsch K, Hopf HC, Galland J. Changes of sensory conduction velocity and refractory periods with decreasing tissue temperature in man. $J$ Neurol 1977;216:181-8.
13 Bolton CF, Carter K, Koval JJ. Temperature effects on conduction studies of normal and abnormal nerve. Muscle Nerve 1982;5:145-7.

14 Koczocik-Przedpelska J, Gorski S, Powierza E. Relationship between sensory nerve conduction and temperature of the hand. Acta Physiol Pol 1983;34:21-28.

15 Geerlings AHC, Mechelse K. Temperature and nerve conduction velocity, some practical problems. Electromyograph Clin Neurophysiol 1985;25:253-60.

16 Lang HA, Puusa A, Hynninen P, Kuusela V, Jantti V, Sillanpaa M. Evolution of nerve conduction velocity in later childhood and adolescence. Muscle Nerve 1985; 8:38-43.

17 Buchthal F, Rosenfalck A. Sensory potentials in polyneuropathy. Brain 1971;94:241-62.

18 Thomas PK, Sears TA, Gilliatt RW. The range of conduction velocity in normal motor nerve fibres to the small muscles of the hand and foot. J Neurol Neurosurg Psychiatry 1959;22:175-81.

19 Simpson JA. Fact and fallacy in measurement of conduction velocity in motor nerves. $J$ Neurol Neurosurg Psychiatry 1964;27:381-5.

20 Dixon WJ, Brown MB, Engelman L, et al. BMDP Statistical Software. Berkeley University of California Press. 1985:283-8.

21 Lundberg A. Potassium and the differential thermosensitivity of membrane potential, spike and negative afterpotential in mammalian $\mathrm{A}$ and $\mathrm{C}$ fibres. Acta Physiol Scand 1948;15(50):1-67.

22 Mayer RF. Nerve conduction studies in man. Neurology 1963;13:1021-30.

23 Kimura J. Principles and pitfalls of nerve conduction studies. Ann Neurol 1984;16:415-29.

24 Trojaborg W. Motor nerve conduction velocities in normal subjects with particular reference to the conduction in proximal and distal segments of median and ulnar nerve. Electroencephalogr Clin Neurophysiol 1964;17:314-21.

25 Dioszeghy $P$. Needle and surface recording electrodes in motor and sensory nerve conduction studies. Electromyograph Clin Neurophysiol 1986;26:117-22.

26 Halar EM, DeLisa JA, Soine TL. Nerve conduction studies in upper extremities: Skin temperature corrections. Arch Phys Med Rehab 1983;61:412-6.

27 Dorfman LJ, Bosley TM. Age-related changes in peripheral and central nerve conduction in man. Neurology 1979;29:38-44.

28 Taylor PK. Non-linear effects of age on nerve conduction in adults. $J$ Neurol Sci 1984;66:223-34. 